\title{
THE ABSENCE OF ANNE STEELE SKINNER
}

\section{Carolyn Hardesty}

When Patty Hearst was captured, one of the items in her purse was a key chain or some other trinket that had belonged to Cinque, a long since dead member of the Symbionese Liberation Army. Authorities in the police and press speculated on the object, bleeding it for significance, and in carefully worded remarks allowed ponderous judgments.

I was among those who believed her innocent-a victim of survival through compromise; and as though in her defense, I pored over the contents of my own bag for revealing details. The bit was found. A piece of Bill Duddleston's bathrobe. If suddenly captured for a deed I hadn't committed, or found dead under suspicious circumstances, investigators would be drawn to the challenge of this small terry cloth square of black with gray and white stripes. The astute sleuth would eventually ask the right question of the right person who would characteristically press three straight fingers to his lips, open his eyes wide, then his mouth, and nod as the swatch touched a memory. Madison, Wisconsin, more than a year prior. A birthday party when Bill's housemates, weary of his tattered and sagging bathrobe, had given him a replacement. In honor of the event and to assure them he'd never wear it again, Bill ripped his beloved wrap-around into small squares and passed them out as favors to the party-goers. With that established, the inquiry would move on. Why would this woman, married to another, keep a piece of Bill Duddleston's bathrobe in her bag for over a year? Was there a deep and secret emotional attachment? Are there other clues to trace? And where is Bill Duddleston?

But those may be the wrong questions. The simplest explanation might be that this is a woman who rarely cleans her bag. A professional would have to discard that reason, for such an excuse denies the very function of investigating. For Patty Hearst, that possibility never existed; every trivial shred of her belongings had to be scrutinized by every examiner, each of whom-hope against hope-wanted to unlock her story with the twist of a single object.

But picture this scene: S.L.A. members are living in their eighth apartment in a six month period. The living room is cramped with more people than 
the furniture can seat; table tops are cluttered with ashtrays, empty cigarette packs, matchbooks, bits of paper with lists, maps and scribblings, guns of assorted sizes, ammunition cartridges, empty Big Mac cartons, paper cups, crumpled napkins. Patty moves forward suddenly, whisks an arm across the coffee table, hoists her purse bottom up while all eyes turn to the clinking of paraphernalia falling on the formica surface. Silence shatters the mood and she says, "Pardon me, I need to clean out my purse."

A dilemma for detectives is of course that "physical trivia" can have immense import. Recall the stamp in the movie, Charade. Some of the best mysteries turn on seemingly ordinary items and we do keep otherwise insignificant things near us because of their evocative powers. We may snatch a smooth stone from a beachful after a day we could never forget. Or tuck away a torn envelope which carried a manuscript acceptance. And how many crunchy black flowers are flattened in American Bibles because they were part of our first homecoming dance? But maybe I kept Bill Duddleston's robe handy because it was a great wipe for my sunglasses.

The truth is that most of what's important is not physical at all but lives instead in our minds. How many hours of sleep are lost yearly over the ruminations of a touch, a word, or even an expression? Such particulars design our attitudes, our loyalties, and our actions. Those are the details the inquirers would love to run their fingers through, but indeed are for the private eye alone.

Something uniquely human wants not only to investigate but to collect. We eagerly acquire things which either have important attachments or to which we hope to attach importance. Wedding rings, musical instruments, fresh books with uncracked spines - all of these promise enrichment and a better quality of life. If only we can live up to them. But the best collections are of those moments which exist largely without physical evidence. When circumstances suddenly demand separation, the absence of a friend is comforted only slightly by left-over birthday notes, old photographs, or the back door key I never returned. 